\title{
Perceived and experienced restrictions in participation and autonomy among adult survivors of stroke in Ghana
}

\author{
*Amosun SL ${ }^{1}$, Nyante $\mathrm{GG}^{2}$, Wiredu $\mathrm{EK}^{3}$ \\ 1. Department of Health and Rehabilitation Sciences, Faculty of Health Sciences, University of Cape Town, South Africa \\ 2. Department of Physiotherapy, School of Allied Health Sciences, College of Health Sciences, University of Ghana, Korle \\ $\mathrm{Bu}$, Ghana \\ 3. School of Allied Health Sciences, College of Health Sciences, University of Ghana, Korle Bu, Ghana
}

\begin{abstract}
Background: Many stroke survivors do not participate in everyday life activities.

Objective: To assess the perceived and experienced restrictions in participation and autonomy among adult stroke survivors in Ghana.

Method: The "Impact on Participation and Autonomy Questionnaire" (IPAQ) instrument was administered in a survey of 200 adult stroke survivors to assess perceived restrictions in participation and autonomy, followed by in-depth interviews with a sub-sample on the restrictions they experienced in participation. Results: Perceived restrictions in participation were most prevalent in the domains of education and training (3.46 \pm 0.79$)$, paid or voluntary work (2.68 \pm 0.89$)$, helping and supporting other people (2.20 \pm 0.82$)$, and mobility $(2.12 \pm 0.79)$. There were significant differences in two domains between survivors who received physiotherapy and those who received traditional rehabilitation. Over half of the survivors also perceived they would encounter severe problems in participation in the domains of paid or voluntary work, mobility, and education and training. The sub-sample of stroke survivors $(n=7)$ mostly experienced restrictions in participation and autonomy in going outside the house, working, and in fulfilling family roles.

Conclusion: If these perceptions and experiences are not addressed during rehabilitation, they could further inhibit the full participation and social integration of stroke survivors.
\end{abstract}

Key words: Participation and autonomy, restriction, stroke

African Health Sciences 2013; 13(1): 24 - 31 http://dx.doi.org/10.4314/ahs.v13i1.4

\section{Introduction}

Though many attempts have been made by various governments of Ghana to achieve the goal of integration ${ }^{1}$, persons with disability still face the challenge of coping not only with the disability itself, but with added burdens of inaccessibility and social stigma which erect barriers to their social integration ${ }^{2}$, ${ }^{3}$. Using the International Classification of Functioning, Disability and Health (ICF) as a conceptual framework for rehabilitation, total integration of persons with disability into their communities is a central goal of rehabilitation, and it entails participation or involvement in life situations ${ }^{4}$. Participation is conceived as a dynamic

*Corresponding author:
Prof Seyi L Amosun
Department of Health and Rehabilitation Sciences
Faculty of Health Sciences
University of Cape Town
Anzio Road, Observatory 7925
Republic of South Africa
Tel: 27214066628
E-mail: seyi.amosun@uct.ac.za

complex interaction between the individual with disability, the body functions, functional status, and the contexts in which the individual lives ${ }^{5,6}$. Most of the instruments developed to provide insight into the involvement of persons with disabilities in their communities have been based mainly on the concepts of physical impairments and/or functional limitations ${ }^{4}$. Assuming that how people function in the context of their lives was of more concern to them than actual impairments or difficulties with individual tasks ${ }^{7}$, researchers proposed that estimation of participation restrictions should be assessed from the individual's perspective ${ }^{8}$. Also autonomy was considered an important prerequisite for participation, as it was linked to the right of persons with disabilities to make decisions and to exert control over themselves and their lives ${ }^{9}$.

The experiences of persons with disabilities fall into three rehabilitation chains namely the medical rehabilitation chain which begins after the onset of the disability during which persons with disabilities interact mainly with healthcare professionals ${ }^{10}$. Next is the psychological rehabilitation chain which also 
begins after the onset of the disability, and represents the internal struggles in persons with disabilities towards a new life. The psychological problems encountered are often grounded in the perception held by persons with disabilities that they are different ${ }^{11}$. Lastly is the social rehabilitation chain which documents the experiences of persons with disabilities in a stigmatizing society ${ }^{10}$. The lifelong stigma is classified into "felt" and "enacted" stigma ${ }^{12}$. Enacted stigma manifests as discrimination against the stigmatized person imposed by others, whereas felt stigma is the fear of enacted stigma experienced by the stigmatized person. Felt stigma may result in stigmatized persons volitionally limiting their life experiences and opportunities in an effort to avoid enacted stigma. The "Impact on Participation and Autonomy Questionnaire" (IPAQ) is an instrument that assesses "felt" stigma related to physical disability ${ }^{7}$. Therefore the main purpose of this study was to utilise the IPAQ to describe the perceived restrictions in participation and autonomy in eight domains among adult stroke survivors in Ghana. In addition, in order to assess "enacted" stigma, in-depth interviews were conducted to explore the restrictions experienced in participation by the survivors. We hypothesised that the perceived and experienced restrictions would be similar.

Physical disability from stroke was selected for the purpose of this study because it contributes significantly to mortality and morbidity in Ghana, and the prevalence is on the increase ${ }^{13}$. Consequently, the number of stroke survivors with resultant physical disabilities, may also increase. Routinely, adult stroke patients in Ghana are initially admitted during the acute phase to the two teaching hospitals in Accra and Kumasi, the regional hospitals, or the district hospitals. The patients admitted to the teaching hospitals and the regional hospitals would benefit from physiotherapy, while those admitted to the district hospitals would not receive physiotherapy because the services were not available. Some of these patients could therefore attend neighbouring traditional herbal clinics for rehabilitation. It is common practice in Ghana for stroke survivors or family members to be suspicious of witchcraft when healthcare does not provide the expected results. Consequently, the survivors would turn to traditional healers in preference or in addition to other healthcare services ${ }^{14,15}$, much more in the face of the grossly inadequate numbers of physiotherapists and other rehabilitation personnel ${ }^{16}$. Though traditional healthcare is more often the second recourse to orthodox medicine, individuals have expressed satisfaction with the outcomes of traditional medicine ${ }^{14}$. Therefore this study also explored if there was a difference in perceived restrictions in participation between stroke survivors who received physiotherapy and those who received traditional rehabilitation.

\section{Methods}

A descriptive mixed methods research design ${ }^{17}$ was utilised for this study after obtaining approval from the Faculty of Health Sciences Research Ethics Committee of the University of Cape Town, South Africa (REC REF: 232/2006) and the Ethics Committee of the College of Health Sciences, University of Ghana. The purpose and the relevance of the study were discussed with the physiotherapists in the hospitals and the health care provider in the herbal clinic, and their support for the study was sought. The cross-sectional survey and its purpose were advertised in the out patients' units of the Departments of Physiotherapy in the two teaching hospitals, the two district hospitals, as well as at the traditional rehabilitation clinic. Stroke survivors who came for treatment during the data collection period were invited to take part in the study. Male and female stroke survivors aged between 18 and 65 years, with a first-ever stroke experienced within 3 or more months, were then invited by one of the investigators the research (GGN) to take part. Additional inclusion criteria were a medical diagnosis of stroke, orientation to time and place, ability to speak clearly, as well as able to sign or thumb print the consent form. Stroke survivors who indicated interest were then contacted to ensure they met the inclusion criteria. Stroke survivors who reported that they were not independent in basic activities of daily living (like bathing and dressing) prior to the onset of stroke, were excluded from selection.

The participants finally selected for the survey included stroke survivors who received or were receiving physiotherapy in the two teaching hospitals in Accra and Kumasi (101 survivors), as well as those who received or were receiving rehabilitation from a traditional rehabilitation clinic in the Eastern part of Ghana (97 survivors). The authors were informed that traditional rehabilitation included oral herbal medication and herbal compresses to the affected limbs. Two additional participants had been patients at both the traditional rehabilitation clinic as well as physiotherapy departments in the hospitals. The 
socio-demographic variables of the survivors were obtained (table 1).

After obtaining informed consent, we quantified perceived restrictions in participation and autonomy utilising the English version of the "Impact on Participation and Autonomy Questionnaire" (IPAQ), through face to face interviews by one of the authors (GGN). Similar to the domains and sub domains of the ICF, indicators of perceived restriction and autonomy are covered in nine domains with 32 sub domains. In this study, one of the domains (leisure) was excluded as the survivors could not relate to the concept of leisure for someone with physical disability. The first three of the remaining eight domains were mobility which included getting around where and when an individual desires (four sub domains), self-care which involved engagement in activities of daily living where and when an individual desires (five sub domains), and looking after own's money which involved deciding when and how to spend it (two sub domains). Another three domains were activities in and around the house which includes planning and getting household work done (six sub domains), social life and relationships which related to the quality and frequency of the social relationships of an individual (seven sub domains), and paid or voluntary work which related to the chances of finding or keeping a paid or voluntary job (five sub domains). The last two domains were education and training which related to the chances of getting the education or training an individual wants (one sub domain), and helping and supporting other people which related to opportunities to help and support other people such as family, neighbours, friends or members of a club (one sub domain). The perceived restrictions in participation and autonomy in each of the sub domains were graded on a 5-point scale ranging from very good (0) to very poor (4). Indicators of personal burden of a perceived problem in participation in each of the nine domains were estimated on a 3-pont rating scale, ranging from no problem (0) to severe problems (2). A s u b sample of ten participants were later purposively selected, and invited to partake in in-depth interviews (conducted by GGN) to describe the restrictions they had experienced in participation. However, only seven survivors (aged 40 to 60 years) attended the interviews. Since the survivors had earlier taken part in the survey, the interviews mainly comprised of probing questions focusing on their personal experiences in restrictions in participation. Three of the seven survivors were receiving physiotherapy, while four were receiving traditional rehabilitation. The recorded interviews were later transcribed.

For each of the eight domains and sub domains, the mean scores in perceived restriction for all the 200 survivors were calculated. Also the standardized mean (domain scores divided by the number of sub domains) was calculated for each domain. Higher scores denoted more restrictions in participation. For each domain, the t-test for unequal samples sizes was used to determine if there were differences in the mean scores between survivors who received physiotherapy and those who received traditional rehabilitation. Also the proportion of survivors who perceived problems in participation in each domain was calculated and analysed using chi-square.

Finally the transcripts of the in-depth interviews were read and re-read, and the experiences were categorised into the eight domains of the IPAQ. Data were then examined for recurrent themes using the content analysis procedure ${ }^{17}$. For each domain, the experiences that best reflected the experiences of other participants were selected and presented.

\section{Results}

The average age of the survivors $(\mathrm{N}=200)$ was $53.7 \pm 7.9$ years. There were no significant differences $(p>0.05)$ in the socio-demographic characteristics between the survivors who received physiotherapy and those who received traditional rehabilitation (table 1). In table 2, perceived restriction in participation was highest in the domains of education and training (3.46 \pm 0.79$)$, paid or voluntary work (2.68 \pm 0.89$)$, helping and supporting other people $(2.20 \pm 0.82)$, and mobility $(2.12 \pm 0.79)$. There were statistically significant differences in perceived restriction in participation and autonomy between survivors in the two rehabilitation groups in the domains of mobility $(\mathrm{p}<0.02)$ and helping and supporting others $(\mathrm{p}<0.01)$. Participation was perceived relatively poorer in two domains for participants who received physiotherapy, namely mobility, and in activities in and around the house. In the remaining six domains, participation was perceived relatively poorer among those who received traditional rehabilitation. 
Table 1: Socio-demographic characteristics of the stroke survivors $(n=200)$

\begin{tabular}{|c|c|c|c|c|}
\hline \multirow[t]{2}{*}{ Characteristics } & \multirow{2}{*}{$\begin{array}{l}\text { Total participants } \\
(n=200)\end{array}$} & \multicolumn{2}{|c|}{ Type of rehabilitation received } & \multirow[b]{2}{*}{$\begin{array}{l}\text { Combined } \\
(n=2)\end{array}$} \\
\hline & & $\begin{array}{l}\text { Physiotherapy } \\
(\mathrm{n}=101)\end{array}$ & $\begin{array}{l}\text { Traditional } \\
(\mathrm{n}=97)\end{array}$ & \\
\hline Female & $100(50 \%)$ & $48(47.5 \%)$ & $51(52.6 \%)$ & $1(50 \%)$ \\
\hline Male & $100(50 \%)$ & $53(52.5 \%)$ & $46(47.4 \%)$ & $1(50 \%)$ \\
\hline \multicolumn{5}{|l|}{ Age (years) } \\
\hline $28-38$ & $11(5.5 \%)$ & $5(4.9 \%)$ & $6(6.1 \%)$ & \\
\hline $39-48$ & $31(15.5 \%)$ & $16(15.8 \%)$ & $15(15.5 \%)$ & \\
\hline $49-58$ & $89(44.5 \%)$ & $44(43.6 \%)$ & $43(44.3 \%)$ & $2(100 \%)$ \\
\hline $59-65$ & $69(34.5 \%)$ & $36(35.6 \%)$ & $33(34.0 \%)$ & \\
\hline \multicolumn{5}{|l|}{ Marital status } \\
\hline Divorced & $25(12.5 \%)$ & $15(14.9 \%)$ & $10(10.3 \%)$ & \\
\hline Married & $137(68.5 \%)$ & $69(68.3 \%)$ & $66(68.0 \%)$ & $2(100 \%)$ \\
\hline Never married & $4(2.0 \%)$ & $2(2.0 \%)$ & $2(2.1 \%)$ & \\
\hline Separated & $6(3.0 \%)$ & $6(5.9 \%)$ & $0(0.0 \%)$ & \\
\hline Widowed & $28(14.0 \%)$ & $9(8.9 \%)$ & $19(19.6 \%)$ & \\
\hline \multicolumn{5}{|l|}{ Educational level } \\
\hline None & $49(24.5 \%)$ & $18(17.8 \%)$ & $30(30.9 \%)$ & $1(50 \%)$ \\
\hline Primary & $41(20.5 \%)$ & $20(19.8 \%)$ & $20(20.6 \%)$ & $1(50 \%)$ \\
\hline Secondary & $53(26.3 \%)$ & $27(26.7 \%)$ & $26(26.8 \%)$ & \\
\hline Post-secondary & $57(28.5 \%)$ & $36(35.6 \%)$ & $21(21.6 \%)$ & \\
\hline \multicolumn{5}{|l|}{ Employment } \\
\hline House wife & $2(1.0 \%)$ & $1(1.0 \%)$ & $1(1.0 \%)$ & \\
\hline Retired & $4(2.0 \%)$ & $1(1.0 \%)$ & $3(3.1 \%)$ & \\
\hline Paid employment & $63(31.5 \%)$ & $40(39.6 \%)$ & $23(23.7 \%)$ & \\
\hline Self-employment & $56(28.0 \%)$ & $24(23.8 \%)$ & $31(32.0 \%)$ & $1(50 \%)$ \\
\hline Unemployed & $75(37.5 \%)$ & $35(34.6 \%)$ & $39(40.2 \%)$ & $1(50 \%)$ \\
\hline \multicolumn{5}{|l|}{ Household } \\
\hline $\begin{array}{l}\text { Living with extended } \\
\text { family }\end{array}$ & $88(44.0 \%)$ & $42(41.6 \%)$ & $46(47.4 \%)$ & \\
\hline $\begin{array}{l}\text { Living with nuclear } \\
\text { family }\end{array}$ & $108(54.0 \%)$ & $56(55.4 \%)$ & $50(51.5 \%)$ & $2(100 \%)$ \\
\hline Staying alone & $4(2.0 \%)$ & $3(3.0 \%)$ & $1(1.0 \%)$ & \\
\hline \multicolumn{5}{|c|}{ Duration of stroke (months) } \\
\hline $3-6$ & $65(32.5 \%)$ & $31(30.7 \%)$ & $34(35.1 \%)$ & \\
\hline $7-12$ & $56(28.0 \%)$ & $29(28.7 \%)$ & $27(27.8 \%)$ & \\
\hline $13-18$ & $20(10.0 \%)$ & $10(9.9 \%)$ & $9(9.3 \%)$ & $1(50 \%)$ \\
\hline $19-24$ & $23(11.5 \%)$ & $9(9.3 \%)$ & $9(.3 \%)$ & \\
\hline Above 24 & $36(18.0 \%)$ & $18(18.6 \%)$ & $18(18.6 \%)$ & $1(50 \%)$ \\
\hline \multicolumn{5}{|c|}{ Rehabilitation (months) } \\
\hline $1-6$ & $79(39.5 \%)$ & $37(36.6 \%)$ & $41(42.3 \%)$ & $1(50 \%)$ \\
\hline $7-12$ & $55(27.5 \%)$ & $31(30.7 \%)$ & $24(24.7 \%)$ & $1(50 \%)$ \\
\hline $13-18$ & $20(10.0 \%)$ & $10(9.9 \%)$ & $9(9.3 \%)$ & \\
\hline $19-24$ & $22(11.0 \%)$ & $13(12.9 \%)$ & $9(9.3 \%)$ & \\
\hline Above 24 & $24(12.0 \%)$ & $10(9.9 \%)$ & $14(14.4 \%)$ & \\
\hline
\end{tabular}


Table 2: Standardised mean scores in perceived restrictions in participation and autonomy

\begin{tabular}{|c|c|c|c|c|}
\hline \multirow[b]{2}{*}{ IPA domains } & \multirow{2}{*}{$\begin{array}{l}\text { Total participants } \\
(\mathrm{n}=200)\end{array}$} & \multicolumn{2}{|c|}{ Type of rehabilitation received } & \multirow[b]{2}{*}{ p-value } \\
\hline & & $\begin{array}{l}\text { Physiotherapy } \\
(\mathrm{n}=101)\end{array}$ & $\begin{array}{l}\text { Traditional } \\
(\mathrm{n}=97)\end{array}$ & \\
\hline \multicolumn{5}{|l|}{ Mobility (4 sub domains) } \\
\hline Standardized mean ${ }^{*}(\mathrm{sd})$ & $2.12(.79)(\mathrm{n}=186)$ & $2.26(0.77)(\mathrm{n}=91)$ & $1.98(0.81)(n=94)$ & $0.02^{+}$ \\
\hline \multicolumn{5}{|l|}{ Self-care (5 sub domains) } \\
\hline Standardized mean (sd) & $1.27(0.52)$ & $1.27(0.53)$ & $1.29(0.52)$ & 0.75 \\
\hline \multicolumn{5}{|c|}{ Activities in $\&$ around the house ( 6 sub domains) } \\
\hline Standardized mean (sd) & $1.72(0.65)$ & $1.75(0.65)$ & $1.70(0.65)$ & 0.70 \\
\hline \multicolumn{5}{|c|}{ Looking after own money (2 sub domains) } \\
\hline Standardized mean (sd) & $1.67(0.79)$ & $1.56(0.72)$ & $1.76(0.84)$ & 0.07 \\
\hline \multicolumn{5}{|c|}{ Social life $\&$ relationships ( 7 sub domains) } \\
\hline Standardized mean (sd) & $1.39(0.56)$ & $1.34(0.57)$ & $1.45(0.55)$ & 0.12 \\
\hline \multicolumn{5}{|c|}{ Paid or voluntary work (5 sub domains) } \\
\hline Standardized mean (sd) & $2.68(0.89)$ & $2.63(0.85)$ & $2.72(0.93)$ & 0.47 \\
\hline \multicolumn{5}{|c|}{ Education \& Training (1 sub domain) } \\
\hline Standardized mean (sd) & $3.46(0.79)$ & $3.41(0.82)$ & $3.51(0.73)$ & 0.27 \\
\hline \multicolumn{5}{|c|}{ Helping \& supporting others ( 1 sub domains) } \\
\hline Standardized mean (sd) & $2.20(0.82)$ & $2.06(0.78)$ & $2.35(0.85)$ & $0.01^{+}$ \\
\hline
\end{tabular}

${ }^{\text {*}}$ Standardized mean $=$ total scores in a domain divided by the number of sub domains

${ }^{+}$Statistically significant difference in mean scores $(\mathrm{p}<0.05)$

In table 3, over half of the survivors perceived they would encounter severe problems in participation in the domains of paid or voluntary work $(66.0 \%)$, mobility $(57.5 \%)$, and education and training (50.9\%). Higher proportions of stroke survivors who received traditional rehabilitation perceived they would encounter severe problems while participating in six domains, but there were significant differences $(\mathrm{p}<0.5)$ in only two domains namely helping and supporting others, and engaging in activities in and around the house.

Table 3: Proportion of stroke survivors who perceived severe problems in participation in domains

\begin{tabular}{|c|c|c|c|}
\hline \multirow[b]{2}{*}{ IPA domains } & \multicolumn{3}{|c|}{ Type of rehabilitation } \\
\hline & $\begin{array}{l}\text { Total group }(\mathrm{n}=200) \\
\mathrm{n}(\%)\end{array}$ & $\begin{array}{l}\text { Physiotherapy }(\mathrm{n}=101) \\
\mathrm{n}(\%)\end{array}$ & $\begin{array}{l}\text { Traditional }(\mathrm{n}=97) \\
\mathrm{n}(\%)\end{array}$ \\
\hline Mobility & $115(57.5)$ & $62(61.4)$ & $52(53.6)$ \\
\hline Self-care & $29(14.9)$ & $13(12.9)$ & $16(17.4)$ \\
\hline Activities in \& around the house ${ }^{*}$ & $52 / 192(27.1)$ & $22(21.8)$ & $29 / 89(32.6)$ \\
\hline Looking after own money & $46 / 195(23.6)$ & $20(19.8)$ & $25 / 92(27.2)$ \\
\hline Social life \& relationships & $39(19.5)$ & $18(17.8)$ & 21 (21.6) \\
\hline Paid or voluntary work & $132(66.0)$ & $69(68.3)$ & $62(63.9)$ \\
\hline Education and training & $59 / 116(50.9)$ & $38 / 80(47.5)$ & $21 / 35(60.0)$ \\
\hline Helping \& supporting others* & $68 / 198(34.3)$ & $25 / 101(24.8)$ & $41 / 95(43.2)$ \\
\hline
\end{tabular}


Collating the experiences, the survivors encountered restrictions in participation in mainly three domains, namely going outside the house, engagement in paid work, and participation in family and social activities. The restrictions that inhibited the survivors from going outside their homes included environmental barriers, and self- and family-imposed restrictions. A survivor described his encounter with environmental barriers -

"Because of this illness I'm not able to worship God as I would have liked to ... I was a very active member of the men's fellowship in [my] church, now I'm not able to go to church. Before I can enter the church premises, I have to be carried like a baby. I have stopped going to church. The pastor has been visiting very often to pray with me and give me communion. I have been facing this problem of climbing stairs even when I go to the bank. Where ever I go, I have to go with someone. Last week for example, my wife travelled and I wanted to go to the bank. So I had to bire someone to assist me. I paid the person's transportation and gave the person some money."

Environmental barriers led to self-imposed restriction for another survivor -

"I am not able to walk to family gatherings. Even if I hired a taxi to take me there, it cannot go directly to the place. People still have to assist me to walk to the place. That is why I have decided not to go to those gatherings. It worries me that I'm not able to meet with the elders of my family to discuss family issues."

Another survivor described family-imposed restriction -

"My children do not allow me to go out again for they think. I may fall down ... and the whole process will start again and may even worsen. I am now recovering, so I can't allow this problem to start all over again."

The restrictions encountered in participating in paid work were either self-imposed or family-imposed

$-$

"When I am well or healed, I will go to work because I have not had what I want in life. I can now walk, without being tired, so all that is left is with my right hand. If I'm able to use both hands to work I can do whatever I want to do. I want to recover fully. I was a driver in the city ... I have not been able to drive for almost two years now. I can now use my band to eat. I don't want to say I am well because I am not able to raise my right hand. I want to raise the right hand to the same level as the left before I can start work."

"I really don't know the type of job I can do at this age, and with this condition it is really a problem. I don't think I can do any strenuous work. I don't want to involve myself in any strenuous activity or anything that will add stress to my life. I just want to be careful not to get another attack. I have asked my sisters and other friends for some loan so that I can start a trade, but they have refused because they are afraid that I will suddenly fall sick again and I can't pay back the loan."

The restrictions encountered in participating in family and social domains were mostly self-imposed "This is not a good sickness and people say it cannot be cured. I don't want people to see me because an evil eye may worsen my condition. Our forefathers say it is an evil disease. Now that I can walk, I am going to seek spiritual assistance before I start involving myself in any activity, to protect myself from another evil attack."

"Some people say I am proud and that is why I have the stroke. So I don't go near them. I don't even want to go out. I don't want to visit people because they may think I am there to beg for money."

"T always feel dejected when I'm in the house. My own relatives avoid me. Whenever I ask them the reason for avoiding me, all that they say is that I am sick, so they don't want to bother me. But I think they should regard me as part of them. If I hear these words, I felt neglected."

"... when I recovered a bit, I had a meeting with the elders of the community. I could not stand to talk to them. There were chiefs and their elders, but I had to sit and talk. It is never allowed but I could not stand. I would have disgraced myself further by falling. I had to sit and talk. I'm not going for such meetings again. I can't disgrace myself. I don't have any control over my own body. What a disgrace!"

\section{Discussion}

The sample for this study was not representative of the whole population of adult stroke survivors in Ghana as there were others in communities who may not be receiving any form of rehabilitation. Also the impairments of the survivors were not assessed to determine if these contributed to the restrictions perceived or experienced. Inferences from the study should therefore be made with necessary caution.

Participation restriction relates to the social impact of disability in terms of an individual's level of participation in different activity domains ${ }^{4}$.The outcome of this study suggested that stroke survivors experienced both felt and enacted stigma. The survivors perceived they would encounter restrictions in participation and autonomy in each of the eight domains, notably in education and training, and in paid or voluntary work. They also perceived they would encounter severe problems in participation in all the domains, with the highest proportion of 
survivors $(66 \%)$ in the paid or voluntary work domain. These evidences of felt stigma could lead the survivors to volitionally limit their participation in life experiences in order to avoid enacted stigma ${ }^{12}$. If not addressed by the physiotherapists or the providers of traditional rehabilitation, the outcome of the rehabilitation of the survivors could be limited. Also the sub-group of stroke survivors experienced an array of psychological and environmental barriers which included restrictions in participation in activities outside of the house, loss of autonomy ${ }^{9}$ and enacted stigma ${ }^{12}$.

While the domains of the perceived and experienced restrictions were not exactly the same, the combination of the perceptions and experiences could have resulted in lowered self-esteem of the survivors ${ }^{12}$, becoming potential barriers to participation with daunting impact on attempts to enhance the social integration of the survivors. Similarly, there was little difference in the perceived restriction in participation and autonomy between survivors in both rehabilitation groups. It is unclear what could have informed the perceptions of the stroke survivors, as well as the attitudes or behaviours of the people the survivors interacted with. Having an understanding of the factors that inhibit participation and autonomy is vital in developing effective rehabilitation that would ensure the full participation of persons with disability in their communities $^{5,9}$.

\section{Conclusion}

We therefore recommend that physiotherapists and traditional healers involved in the rehabilitation of stroke survivors in Ghana should pay greater attention to the perceived and experienced restrictions in participation, and be skilled to assist stroke survivors and their family members to identify and overcome the perceived restrictions.

\section{References}

1. National Disability Policy Document- Ghana. 2000. (http://www.disability.dk/site/ viewdoc.php?doc_id $=208 \&$ section_id $=6$ (Accessed 2010, June 27).

2. Agbenyega JS, Deppeler J, Harvey D. Attitudes towards inclusive education in Africa Scale (ATIAS): An Instrument to measure teachers' attitudes towards inclusive education for students with disabilities. Journal of Research and Development in Education, 2005; 5: 1 - 15.
3. Avoke M. Models of disability in the labelling and attitudinal discourse in Ghana. Disability and Society, 2002; 17(7): 769 - 777.

4. Lund ML, Nordlund A, Nygard L, Lexell J, Bernspang B. Perceptions of participation and predictors of perceived problems with participation in persons with spinal cord injury. Journal of Rehabilitation Medicine, 2005; 37: 3 - 8.

5. D’Alisa S, Baudo S, Mauro A, Miscio G. How does stroke restrict participation in long-term post stroke survivors? Acta Neurologica, 2005; 112(3): 157 - 162.

6. Fallahpour M, Jonsson H, Joghataei MT, Kottorp A. Impact on participation and autonomy: Psychometric evaluation of the Persian version to use for persons with stroke. Scandinavian Journal of Occupational Therapy, 2011; 18(1): $59-71$.

7. Cardol M, de Haan RJ, de Jong BA, van den Bos GAM, de Groot IJM. Psychometric properties of the impact on Participation and Autonomy Questionnaire. Archives of Physical Medicine and Rehabilitation, 2001; 82(2): 210 - 216.

8. Wilkie R, Peat G, Thomas E, Croft P. The prevalence of person-perceived participation restriction in community-dwelling older adults. Quality of Life Research, 2006; 15(9): 1471 - 1479.

9. Hammel J, Magasi S, Heinemann A, Whiteneck G, Bogner J, Rodriguez E. What does participation mean? An insider perspective from people with disabilities. Disability and Rehabilitation, 2008; 30(19): 1445 - 1460.

10. Lund ML, Tamm M. How a group of disabled persons experience rehabilitation over a period of time. Scandinavian Journal of Occupational Therapy, 2001; 8: 96 - 104.

11. De Klerk HM, Ampousah L. The physically disabled woman's experience of self. Disability and Rehabilitation, 2003; 25: 1132 - 1139.

12. Tagoe HA, Dake FAA. Healthy lifestyle behaviour among Ghanaian adults in the phase of a health policy change. Globalization and Health, 2011; 7:7. http:// www.globalizationand health.com/content $/ 7 / 1 / 7$

13. Lemogoum D, Degaute JP, Bovet P. Stroke prevention, treatment, and rehabilitation in subSaharan Africa. American Journal of Preventive Medicine, 2005; 29(5): S95 - S101

14. Sato A. Revealing the popularity of traditional medicine in light of multiple recourses and outcome measurements from a user's 
perspective in Ghana. Health Policy and Planning, 2012; doi: 10.1093/heapol/czs010

15. Tabi MM, Powell M, Hodnicki D. Use of traditional healers and modern medicine in Ghana. International Nursing Review, 2006; 53(1): $52-58$.
16. Tinney MJ, Chiodo A, Haig A, Wiredu E. Medical rehabilitation in Ghana. Disability and Rehabilitation, 2007; 29(11-12): 921 - 927.

17. Rauscher L, Greenfield BH. Advancements in contemporary physical therapy research: Use of mixed methods designs. Physical Therpy 2009; 89(1): 91-100 